\title{
Seleção de progênies $F_{4}$ de cafeeiros obtidas pelo cruzamento de Icatu com Catimor
}

\author{
César Elias Botelho ${ }^{1}$, Antônio Nazareno Guimarães Mendes², Gladyston Rodrigues Carvalho ${ }^{3}$, Gabriel Ferreira \\ Bartholo $^{4}$, Samuel Pereira Carvalho
}

\begin{abstract}
RESUMO
Com o objetivo de selecionar progênies de cafeeiros produtivos e resistentes à ferrugem foi instalado e conduzido um experimento em Machado,MG. Foram avaliadas 29 progênies selecionadas pelo programa de melhoramento genético do cafeeiro, coordenado pela EPAMIG, obtidas a partir do cruzamento Icatu e Catimor. O cultivar Rubi MG 1192 foi utilizado como testemunha. O delineamento experimental adotado foi o de blocos casualizados, com três repetições. Foram analisados a produção de café beneficiado em sc.ha-1 de seis colheitas, 2001/2002 a 2006/2007; o vigor vegetativo avaliado após a colheita 2006/2007; e a incidência e severidade da ferrugem no primeiro semestre de 2006. Observouse variabilidade para produção e resistência à ferrugem, resultados confirmados pelas estimativas da herdabilidade de boa magnitude, variando de 58,5\% para a produção a 92,6\% para a característica incidência da ferrugem. Esses resultados, aliados às boas médias de produção, à baixa incidência e severidade da ferrugem ao bom vigor vegetativo de algumas progênies, demonstram que é possível selecionar progênies superiores com base na produção e resistência à ferrugem.
\end{abstract}

Palavras chave: Café, melhoramento, resistência, ferrugem

\begin{abstract}
Selection of $\mathrm{F}_{4}$ coffee progenies, obtained from Icatu x Catimor cross

The objective of this work was to select progenies of productive and rust resistant coffee plants. An experiment was installed and carried out in Machado, MG, Brazil, where 29 progenies obtained from the Icatu x Catimor cross were evaluated and selected by the coffee plant genetic improvement program coordinated by EPAMIG. Cultivar Ruby MG 1192 was used as control. The experiment was arranged in a randomized block design with three repetitions. Production of processed coffee in 60 kg bags.ha ${ }^{-1}$ from six harvests, from 2001/2002 to 2006/2007, vegetative vigor evaluated after the 2006/2007 harvest and the incidence and severity of rust in the first semester of 2006 were analyzed. Variability was observed for production and rust resistance, which was confirmed by heredability estimates of good magnitude, varying from $58.5 \%$ for production to $92.6 \%$ for rust incidence. These results allied to good production means, low rust incidence and severity and good vegetative vigor of some progenies, show that it is possible to select superior progenies on the basis of production and rust resistance.
\end{abstract}

Key words: Coffee, improvement, resistance, rust

Recebido para publicação em agosto de 2008 e aprovado em março de 2010

${ }^{1}$ Engenheiro Agrônomo, Doutor. Unidade Regional Epamig Sul de Minas, Epamig, Campus da UfLA, Caixa Postal 176, 37200-000, Lavras, Minas Gerais, Brasil. cesarbotelho@epamig.br

${ }^{2}$ Engenheiro Agrônomo, Doutor. Departamento de Agricultura, UfLA, Caixa postal 3037, 37200-000, Lavras, Minas Gerais, Brasil. naza@.ufla.br

${ }^{3}$ Engenheiro Agrônomo, Doutor. Unidade Regional Epamig Sul de Minas, Epamig, Campus da UFLA, Caixa Postal 176, 37200-000, Lavras, Minas Gerais, Brasil. uflacarvalho@epamig.br

${ }^{4}$ Engenheiro Agrônomo, Doutor. ABACAFÉ, Rua Paraíba, 416, Luis Eduardo Magalhães, Bahia, Brasil. gbartholo@gmail.com

${ }^{5}$ Engenheiro Agrônomo, Doutor. Departamento de Agricultura, Universidade Federal de Lavras, Caixa postal 3037, 37200-000, Lavras, Minas Gerais, Brasil. samuelpc@dag.ufla.br

Rev. Ceres, Viçosa, v. 57, n.3, p. 274-281, mai/jun, 2010 


\section{INTRODUÇÃO}

Entre os diversos obstáculos encontrados pelos cafeicultores no processo de produção, destaca-se a ocorrência de diversas doenças e pragas, responsáveis por prejuízos econômicos devidos à redução da longevidade das lavouras, da qualidade dos frutos e, principalmente, da produtividade (Carvalho \& Chalfoun, 1998). A ferrugem, causada pelo fungo Hemileia vastatrix Berk. et Br., na maioria das regiões produtoras do Brasil, é considerada a principal doença do cafeeiro, podendo ocasionar redução de 30 a 45\% da produção, quando na ausência de medidas de controle (Carvalho \& Chalfoun, 1998; Matiello, 1991). Em lavouras adultas, a doença causa desfolha das plantas, causando redução na área fotossinteticamente ativa, ocasionando a morte dos ramos laterais, afetando o florescimento, o pegamento de frutos e, consequentemente, a produção no ano seguinte (Chalfoun \& Zambolim, 1985).

O método de controle predominante é o químico, que, embora eficiente, eleva os custos de produção e também põe em risco a saúde dos trabalhadores e o ambiente. Dessa forma, tem-se dado ênfase nos programas de melhoramento genético do cafeeiro à obtenção de cultivares resistentes à ferrugem, que possam dispensar total ou parcialmente a aplicação de fungicidas (Várzea et al., 2002).

A maioria dos cultivares melhorados, resistentes à ferrugem, atualmente em uso tem como fonte de resistência o material denominado Híbrido de Timor (Várzea et al., 2002). Pela similaridade com os cultivares de Coffea. arabica e sua resistência à ferrugem, o material do Híbrido de Timor é muito utilizado como genitor na obtenção de cultivares de café resistentes à ferrugem (CastilhoZapata \& Moreno-Ruiz, 1981; Carvalho et al., 1989; Carvalho et al., 1991; e Pereira, 1995). Em trabalho de avaliação de progênies $F_{4}$ resultantes do cruzamento entre Catuaí Amarelo com Híbrido de Timor em São Sebastião do Paraíso, Minas Gerais, Pereira et al. (2001) obtiveram resultados que indicam ser possível obter progênies com produção elevada e estáveis, com grande potencial para obtenção de cultivares de porte baixo e resistentes à ferrugem. Resultados semelhantes foram obidos por Bonomo et al. (2004), em estudo com 28 progênies $F_{3}$ do cruzamento entre Catuaí Vermelho e Catuaí Amarelo com Híbrido de Timor, em Patrocínio, Minas Gerais. Os autores identificaram progênies produtivas aliadas à estimativa elevada de variância genética.

Entre as populações resistentes à ferrugem originadas de cruzamentos com o Híbrido de Timor, destaca-se o Catimor. Ele reúne grande diversidade genética de resistência à ferrugem e tem produção de frutos semelhante à das seleções do cultivar Catuaí (Severino et al., 2000). Moura et al. (2001), avaliando diferentes progênies de café, inclusive 13 seleções do grupo Catimor, em Patrocínio, Minas Gerais, identificaram progênies de Catimor promissoras quanto à produtividade, com produções acima de 30 sacos.ha ${ }^{-1}$, iguais aos cultivares Rubi MG 1192, Topázio MG 1190, Catuaí Vermelho IAC 15 e Icatu Amarelo IAC 2944.

Outro germoplasma de grande importância nos programas de melhoramento visando resistência à ferrugem é o cultivar Icatu, caracterizado pela rusticidade,pelo alto vigor vegetativo, pela boa produção e variabilidade na resistência á ferrugem específica e não-específica (Fazuoli et al., 1983). Alvarenga et al. (1998) avaliaram 10 progênies de Icatu quanto à produção em quatro colheitas e a resistência à ferrugem, por meio de escala de notas proposta por Costa (1978). Os autores concluíram que as progênies de Icatu são, em geral, tão produtivas quanto os cultivares comerciais Catuaí Vermelho IAC 44 e Mundo Novo CP 500-11, utilizados como testemunha no experimento, tendo sido que a maioria deles classificados como resistente ou moderadamente resistente. Também Correa (2004), em trabalho com progênies de Icatu, em três locais do Sul de Minas Gerais e durante oito colheitas consecutivas, concluiu que as progênies de 'Icatu' com prefixos IAC 4040-181, IAC 4040-315, IAC 4042-114, IAC 4042-222 e IAC 4045-47 mostraram-se promissoras, por apresentarem produção média alta, aliada à adaptabilidade e à estabilidade para essa característica.

Na seleção de cafeeiros resistentes à ferrugem, tem-se dado ênfase à resistência vertical ou específica. Esse tipo de resistência, relacionada à expressão de número reduzido de natureza dominante, é mais fácil de ser trabalhada em programas de melhoramento (Chaves, 1976). Por outro lado, ela tem caráter temporário, ocorrendo frequentes quebras da resistência, devido a adaptações do patógeno ao genótipo (Eskes, 1980).

A reação do hospedeiro também pode ser explicada por meio de controle genético mais complexo, conferindo resistência denominada resistência horizontal (Van der Plank, 1968) ou não-específica (Zadoks, 1972).

A resistência não-específica caracteriza-se por ser poligênica, pela expressão incompleta, ligada a mecanismos que dificultam o desenvolvimento do patógeno, resultam em menor número de lesões, lesões menores com menos esporos e maior período infeccioso (Van der Plank, 1963).

Robson (1979), citado por Almeida (1980), sugeriu a possibilidade de se obterem cafeeiros com resistência nãoespecífica. A viabilidade da estratégia pode ser proporcionada pela existência de germoplasma apresentando esse tipo de resistência, como o Icatu (Costa \& Ribeiro, 1975; Eskes \& Costa, 1983) e Híbrido de Timor e seus derivados (Almeida, 1980; Barbosa et al., 2005). 
Em condições naturais de epidemia, o número de pústulas por folha infectada é a característica que melhor discrimina níveis de resistência horizontal em cultivares de C. arabica (Ribeiro et al., 1981).

A estimativa dos componentes genéticos é muito importante em programas de melhoramento, pois permite conhecer a natureza da ação dos genes envolvidos no controle dos caracteres quantitativos e também avaliar a eficiência da estratégia de melhoramento adotada. Dentre os parâmetros de maior importância, destacam-se as variâncias, as correlações e a herdabilidade (Cruz \& Carneiro, 2003). Um dos requisitos para o sucesso na seleção é que a herdabilidade do caráter em questão seja alta, ou seja, a maior parte da variação fenotípica deve ser em função da ação dos genes. No caso do cafeeiro, alguns valores de herdabilidade para a produção de grãos encontrados na literatura variam de 37 a 57\%, conforme Srinivasan et al. (1979), de 61 a 93\% (Fazuoli et al., 2000); e de 71 a 80\% (Bonomo et al., 2004). Para a resistência à ferrugem, Miranda (2003), em avaliação por meio de notas em progênies $F_{6}$ e $F_{7}$ de Catimor, $F_{3}$ do cruzamento Híbrido de Timor x Mundo Novo IAC 379-19 e progênies $F_{4}$ e $F_{5}$ de cruzamentos entre Híbrido de Timor e diversos cultivares de Catuaí, encontrou valores para a herdabilidade no sentido amplo variando $h_{a}^{2}$ entre 12 e $86 \%$.

O objetivo do presente trabalho foi selecionar cafeeiros produtivos e resistentes à ferrugem, num grupo de progênies $F_{4}$ resultantes do cruzamento de seleções de Icatu Vermelho IAC 2942 x Catimor UFV 1340, realizado pela EPAMIG em Machado, MG.

\section{MATERIAL E MÉTODOS}

Foram avaliadas 29 progênies F4, resultantes do cruzamento Icatu Vermelho IAC 2942 x Catimor UFV 1340, ambos genitores resistentes à ferrugem do cafeeiro. $\mathrm{O}$ cultivar Rubi MG-1192, suscetível, foi utilizada como testemunha. As progênies foram obtidas no programa de melhoramento genético do cafeeiro, conduzido em Minas Gerais, coordenado pela Empresa de Pesquisas Agropecuárias de Minas Gerais (EPAMIG) e com a participação da Universidade Federal de Lavras (UFLA) e da Universidade Federal de Viçosa (UFV). O experimento foi instalado em 1999 na Fazenda Experimental da EPAMIG, situada no município de Machado, região Sul do Estado de Minas Gerais, em blocos casualizados, com três repetições e cinco plantas por parcela. $\mathrm{O}$ espaçamento adotado foi de 0,8 $\mathrm{m}$ entre plantas e 3,5 m entre fileiras, correspondendo a 3.570 plantas.ha- ${ }^{-1}$.

O solo da área experimental é classificado como podizólico, textura média. O experimento está situado em uma região de relevo ondulado e a uma altitude de $900 \mathrm{~m}$, latitude de $21^{\circ} 40^{\prime} \mathrm{S}$ e longitude de $45^{\circ} 55^{\prime} \mathrm{W}$. A precipitação pluvial média anual é de 1.670 mm, e temperatura média anual de $19,8^{\circ} \mathrm{C}$.
Foram avaliadas as seguintes características:

Produção de café beneficiado: Produção de frutos, em litros, de "café da roça" por parcela, anualmente, sendo a colheita realizada entre os meses de maio e julho de cada ano. Posteriormente, foi realizada a conversão para sacas de $60 \mathrm{~kg}$ de café beneficiado.ha-1 ${ }^{-1}$ A conversão é realizada por aproximação de valores e consiste em considerar um rendimento médio de 480 litros de "café da roça" para cada saca de $60 \mathrm{~kg}$ de café beneficiado. Em todos os locais foi avaliado um total de seis colheitas, safras 2001/ 2002 a 2006/2007.

Vigor vegetativo: Avaliado a partir da atribuição de notas conforme escala arbitrária de 10 pontos, sendo nota 1 conferida às piores plantas, com o vigor vegetativo muito reduzido e acentuado sintoma de depauperamento e nota 10 às plantas com excelente vigor, mais enfolhadas e com acentuado crescimento vegetativo dos ramos produtivos, conforme sugerido por Carvalho et al. (1979).

Determinação da incidência e severidade da ferrugem: Foram feitas três amostragens de folhas, de março a julho de 2006, e coletadas 10 folhas por planta do terceiro ou quarto par, sendo cinco de cada lado da linha e no terço médio das plantas. A incidência em porcentagem foi estimada pelo número de folhas com sintomas da ferrugem dividido pelo número total de folhas da amostra. Para a avaliação da severidade, utilizou-se o método de contagem de pústulas por folha, determinando-se o número médio de pústulas por folha infectada, que, segundo Ribeiro et al. (1981), é um eficiente método para avaliar a presença de resistência não especifica.

As análises para as características produção de café beneficiado, incidência e severidade da ferrugem foram feitas em esquema de parcelas subdividas no tempo (Steel \& Torrie, 1980), considerando-se subparcelas o conjunto de duas colheitas ou biênio e a época da avaliação da ferrugem, conforme o modelo a seguir. Foi considerado fixo o efeito de biênios ou épocas e os demais aleatórios.

$$
\mathrm{Y}_{\mathrm{ijk}}=\mathrm{m}+\mathrm{p}_{\mathrm{i}}+\mathrm{b}_{\mathrm{j}}+\mathrm{c}_{\mathrm{k}}+(\mathrm{pb})_{\mathrm{ij}}+(\mathrm{pc})_{\mathrm{ik}}+(\mathrm{bc})_{\mathrm{jk}}+\mathrm{e}_{(\mathrm{ijk})},
$$

em que:

$\mathrm{Y}_{\mathrm{ijk}}=$ valor médio da progênie i, do biênio k, no bloco j;

$\mathrm{m}=$ média geral;

$\mathrm{b}_{\mathrm{j}}=$ efeito do bloco $\mathrm{j}(\mathrm{j}=1,2, \ldots, \mathrm{J})$;

$\mathrm{p}_{\mathrm{i}}=$ efeito da progênie i $(\mathrm{i}=1,2, \ldots, \mathrm{I})$;

$c_{k=}$ efeito do biênio ou época $k(k=1,2, \ldots, K)$;

$(\mathrm{pb})_{\mathrm{ij} j}$ efeito da interação da progênie i com o bloco j;

(pc) $)_{\mathrm{i} k=}$ efeito da interação da progênie i com o biênio ou época k;

(bc) $)_{\mathrm{JK}}=$ efeito da interação do bloco j com o biênio ou época k e

$\varsigma_{\mathrm{ijk}}=$ efeito do erro experimental em nível de subparcelas. 
Os dados relativos a incidência e severidade da ferrugem foram transformados em $\sqrt{\mathrm{x}+0,5}$, após a constatação da falta de normalidade dos erros.

Utilizou-se o seguinte modelo para análise da característica vigor vegetativo:

$\mathrm{Y}_{\mathrm{ijk}}=\mathrm{m}+\mathrm{p}_{\mathrm{i}}+\mathrm{b}_{\mathrm{j}(\mathrm{l})}+\mathrm{e}_{(\mathrm{ij})}$,

em que:

$\mathrm{Y}_{\mathrm{ij}}=$ valor médio da progênie i, no bloco j;

$\mathrm{m}$ = média geral;

$\mathrm{p}_{\mathrm{i}=}$ efeito da progênie $\mathrm{i}(\mathrm{i}=1,2, \ldots, \mathrm{I})$;

$\mathrm{b}_{\mathrm{j}(\mathrm{l})}=$ efeito do bloco $\mathrm{j}(\mathrm{j}=1,2, \ldots, \mathrm{J})$; e

$\mathrm{e}_{(\mathrm{ij})}=$ efeito do erro experimental médio.

Para as estimativas dos componentes de variância, nas análises foram consideradas as esperanças dos quadrados médios, utilizando-se procedimento semelhante ao apresentado por Ramalho et al. (2000).

Para as análises de variâncias dos dados adotaram-se significâncias de 5 e de $1 \%$ de probabilidade para o teste F. As análises foram feitas utilizando-se o programa computacional 'Sisvar', desenvolvido por Ferreira (2000). Quando diferenças significativas foram dectadas, as médias foram agrupadas pelo teste de Skott-Knott, a 5\% de probabilidade.

Com as estimativas das variâncias genética e fenotípica foi possível obter a herdabilidade no sentido amplo para as características produção de café beneficiado e incidência e severidade da ferrugem, por meio da expressão = , em que é a progênie e a variância fenotípica. Para a característica produção, também foi estimado o ganho esperado com a seleção, considerando as seis melhores progênies de cada ambiente. Utilizou-se, para estimar o ganho com a seleção, a expressão GS = ds., em que ds é o diferencial de seleção, que corresponde à diferença entre a média geral das progênies e a média das progênies selecionadas.

\section{RESULTADOS E DISCUSSÃO}

As análises de variância para produção, incidência e severidade da ferrugem foram realizadas utilizando-se o esquema de parcelas subdivididas no tempo, como proposto por Steel \& Torrie, (1980). Esse procedimento possibilita o estudo das interações progênies x colheitas e progênies x épocas e o comportamento das progênies, principalmente ao longo das colheitas, com possibilidade de identificar progênies mais ou menos precoces em relação à produção. Além disso, com a análise no esquema de parcela subdividida é possível estimar a variância de progênies ou genética livre da variância da interação, que é mais relevante em relação à produção, pois quando a aná- lise é realizada com base na produção total média, a variância genética é superestimada, pois contém a soma das variâncias de progênies e da interação progênies por colheita (Allard, 1971).

A produção foi analisada por meio da produtividade média em sacas.ha-1 ${ }^{-1}$ ano, obtida pela média de duas colheitas consecutivas combinadas (biênio). Alguns autores relatam que a combinação das colheitas em biênios melhora a precisão experimental, por reduzir os efeitos da bienalidade da produção (Bonomo et al., 2004; Mendes, 1994).

Em relação à avaliação da resistência da ferrugem, a determinação da severidade, além da incidência da ferrugem, é justificada devido a sua importância na seleção de progênies, porque aquelas que apresentarem menor severidade provavelmente toleram mais a doença, devido à menor desfolha. Outro aspecto de relevância é que menor severidade pode indicar resistência horizontal segundo Ribeiro et al. (1981).

Na Tabela 1 são apresentados o resumo da análise de variância e as estimativas dos parâmetros genéticos para as características produtividade, incidência e severidade da ferrugem. Para a característica produtividade, observou-se que houve efeito significativo a $1 \%$ de probabilidade pelo teste $\mathrm{F}$ para fontes de variação progênies, biênios e para a interação progênies x biênios. A existência de interação evidenciou a não-coincidência do comportamento das progênies nos três biênios. Para efeito de seleção de progênies, o resultado de maior interesse foi a presença de diferença significativa entre as progênies, o que juntamente com a estimativa da variância de progênie diferente de zero (7,32), demonstrar que existe variabilidade genética entre as progênies estudadas. A estimativa da foi de $68,53 \%$, considerada alta, de acordo com os valores encontrados na literatura, 35 a 57\%, conforme Srinivasan et al. (1979), de 61 a 93\% (Fazuoli et al. 2000), e de 71,30 a 80,36\% (Bonomo et al. 2004). A boa estimativa da reforçou a observação anterior da presença de variabilidade genética entre progênies e também indicou condição adequada para seleção de progênies. Tal fato foi confirmado pelo valor positivo e de boa magnitude do ganho esperado com a seleção (3,0 sc.ha $\left.{ }^{-1}\right)$, considerando as seis melhores progênies.

Para a incidência e severidade da ferrugem houve efeito significativo em nível de $1 \%$ de probabilidade indicado pelo teste F progênies, épocas e para interação progênies $\mathrm{x}$ biênios. A significância, aliada às estimativas das variâncias de progênies que foram diferentes de zero e positivas $(1,9925$ e 0,0675) para incidência e severidade, respectivamente, indica a existência de variabilidade genética entre as progênies estudadas para a resistência à ferrugem. As estimativas da foram de boa magnitude, $80 \%$ para a incidência e $60,37 \%$ para a severidade, seme- 
lhantes aos valores encontrados por Miranda (2003), entre 12 e $86 \%$. As estimativas das encontradas confirmam a observação anterior da presença de variabilidade genética entre as progênies e também indica condição adequada para seleção de progênies com resistência à ferrugem.

Na Tabela 2 são apresentados os dados sobre o comportamento das progênies em cada biênio e a média geral dos três biênios de produção. Para melhor visualização não foram apresentadas todas as progênies na tabela. Um primeiro resultado destacado foi a diferença entre os biênios, tendo a produção do último biênio sido superior, evidenciando um incremento da produtividade das progênies com o passar das colheitas, indicando que as progênies atingiram o potencial produtivo somente após a quarta colheita, mostrando que a seleção antes dessa época não seria eficiente, considerando que os anos de maior produtividade são os mais favoráveis para a seleção (Bonomo 2004; Fazuoli et al., 2000).

Embora o teste $\mathrm{F}$ tenha sido significativo para o desdobramento de progênies dentro do terceiro biênio, o teste de agrupamento de médias não detectou essa diferença. Quando se considerou a média dos três biênios de produção, notou-se que houve diferença entre as progênies com a formação de dois grupos: um inferior, composto por 15 progênies, incluindo o cultivar utilizado como testemunha (Rubi MG 1192), embora não tenha sido realizado controle da ferrugem, o que pode ter interferido negativamente na produção da testemunha, cultivar suscetível à ferrugem. O outro, composto por progênies superiores, foi formado por 15 progênies, que apresentaram

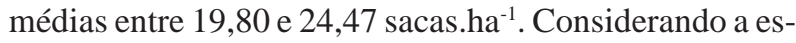
timativa de herdabilidade anteriormente apresentada e o bom nível de vigor vegetativo, aliado à média de produtividade alta, superior à do cultivar Rubi MG 1192, as progênies do grupo superior apresentam bom potencial para seleção. O bom desempenho em relação à produtividade, principalmente quando se considerou o terceiro biênio de avaliação, obtido pelas progênies testadas, foi justificado pelo potencial produtivo dos parentais, conforme relatos encontrados na literatura. Correa (2004), ao trabalhar com 11 progênies de Icatu em dois locais do Sul de Minas, Machado e São Sebastião do Paraíso, obteve produtividade média de oito colheitas, variando de 47,7 a 59,3 sacas.ha-1 ${ }^{-1}$ Também Moura et al. (2001), em avaliação de diferentes populações de café em Patrocínio, MG por três colheitas consecutivas, obtiveram produção média de 38,88 sacas.ha-1 para o cultivar Icatu Amarelo IAC 2944 e entre 20,45 e 30,86 sacas.ha-1 para 13 progênies de Catimor. Embora não se tenha sido detectado diferença significativa para o vigor vegetativo (Tabela 2), chamam atenção os valores, que foram considerados altos, variando de 5,60 a 7,30. O fato de as progênies e a testemunha permanecerem num mesmo grupo pode ser considerado satisfatório, ao considerar que o cultivar Rubi MG 1192 sabidamente apresenta alto vigor vegetativo.

Os resultados para cada época de avaliação e média, tanto para incidência como para severidade, são apresentados na Tabela 3. Ao considerar a média geral de cada época, pode-se observar que houve aumento da incidência da ferrugem ao longo das épocas avaliadas. Esse re-

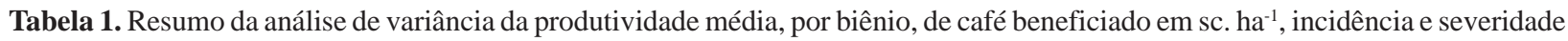
da ferrugem e estimativas de parâmetros genéticos, em Machado, MG

\begin{tabular}{|c|c|c|c|c|}
\hline \multirow{2}{*}{ FV } & \multirow{2}{*}{ GL } & \multicolumn{3}{|c|}{ QM } \\
\hline & & Produção & Incidência $^{1}$ & Severidade $^{1}$ \\
\hline Bloco (B) & 2 & 141,9319 & 4,1083 & 0,4788 \\
\hline Progênie (P) & 29 & $96,1814^{* *}$ & $22,4954 * *$ & $1,0065^{* *}$ \\
\hline Erro a (Bx P) & 58 & 30,2680 & 4,5628 & 0,3986 \\
\hline Biênio/época (C) & 2 & $33717,6640 * *$ & $120,3869 * *$ & $12,0951 * *$ \\
\hline Erro b (B x C) & 4 & 29,8598 & 1,1095 & 0,1973 \\
\hline $\mathrm{P} \times \mathrm{C}$ & 58 & $113,2784 * *$ & $2,2843^{* *}$ & 0,2723 \\
\hline Erro c & 116 & 33,6431 & 1,0645 & 0,2386 \\
\hline Média & & 19,42 & 23,70 & 2,70 \\
\hline \multirow[t]{3}{*}{ CV (\%) } & & a 28,32 & a 49,11 & a 38,03 \\
\hline & & b 28,13 & b 24,22 & b 26,76 \\
\hline & & c 29,86 & c 23,72 & c 29,42 \\
\hline$\sigma_{\mathrm{p}}^{2}:$ & & 7,32 & 1,9925 & 0,0675 \\
\hline$\sigma_{p c}^{2}:$ & & 26,54 & 0,4066 & 0,0112 \\
\hline$\sigma_{\mathrm{F}}^{2}:$ & & 10,68 & 2,4994 & 0,1118 \\
\hline$\sigma_{p}^{2}:$ & & 68,53 & 80,00 & 60,37 \\
\hline $\mathrm{h}^{\mathrm{2}_{\mathrm{a}}^{\mathrm{p}}}:$ & & 3,0 & - & - \\
\hline
\end{tabular}

${ }^{1}$ Dados transformados em $\sqrt{\mathrm{x}+0,5}$

** Significativo, a $1 \%$ de probabilidade, respectivamente, pelo teste $\mathrm{F}$. 
sultado indica um comportamento mais tardio da ferrugem para o ano avaliado e para as condições de Machado, MG e que as três avaliações foram realmente necessárias para estudar o comportamento das progênies em relação à ferrugem. Merece destaque o comportamento de algumas progênies, mais precisamente as identificadas com os números 13 e 15, que apresentaram baixíssimos índices para as duas características nas três épocas avaliadas, confirmando o alto grau de resistência ferrugem progênies.

Tabela 2. Produtividade média e por biênio de café beneficiado em sacas. ha-1 e vigor vegetativo de 30 genótipos de C. arabica avaliados em Machado, MG

\begin{tabular}{llccccc}
\hline Progênie & $\mathbf{N}^{\mathbf{0}}$ & Biênio $\mathbf{1}$ & Biênio $\mathbf{2}$ & Biênio $\mathbf{3}$ & Média & Vigor 2006 \\
\hline H-29-1-3-7 & 02 & $4,41 \mathrm{a} 1$ & $15,17 \mathrm{a} 1$ & $53,38 \mathrm{a} 1$ & $24,32 \mathrm{a} 2$ & $5,70 \mathrm{a} 1$ \\
H-29-1-8-5 & 05 & $3,99 \mathrm{a} 1$ & $12,52 \mathrm{a} 1$ & $56,21 \mathrm{a} 1$ & $24,24 \mathrm{a} 2$ & $6,70 \mathrm{a} 1$ \\
H-30-3-14-19 & 12 & $7,13 \mathrm{a} 1$ & $14,52 \mathrm{a} 1$ & $49,50 \mathrm{a} 1$ & $23,72 \mathrm{a} 2$ & $6,70 \mathrm{a} 1$ \\
H-29-1-3-19 & 04 & $4,60 \mathrm{a} 1$ & $13,37 \mathrm{a} 1$ & $52,38 \mathrm{a} 1$ & $23,45 \mathrm{a} 2$ & $6,30 \mathrm{a} 1$ \\
H-32-11-17-4 & 15 & $5,22 \mathrm{a} 1$ & $8,85 \mathrm{a} 1$ & $54,41 \mathrm{a} 1$ & $22,83 \mathrm{a} 2$ & $7,30 \mathrm{a} 1$ \\
H-136-1-19-4 & 27 & $6,91 \mathrm{a} 1$ & $7,30 \mathrm{a} 1$ & $53,21 \mathrm{a} 1$ & $22,47 \mathrm{a} 2$ & $7,00 \mathrm{a} 1$ \\
H-29-1-14-5 & 08 & $18,01 \mathrm{a} 1$ & $8,90 \mathrm{a} 1$ & $39,04 \mathrm{a} 1$ & $21,98 \mathrm{a} 2$ & $5,60 \mathrm{a} 1$ \\
H-29-1-8-16 & 06 & $4,11 \mathrm{a} 1$ & $12,08 \mathrm{a} 1$ & $48,93 \mathrm{a} 1$ & $21,17 \mathrm{a} 2$ & $7,30 \mathrm{a} 1$ \\
H-136-1-19-7 & 28 & $5,61 \mathrm{a} 1$ & $7,75 \mathrm{a} 1$ & $49,67 \mathrm{a} 1$ & $21,01 \mathrm{a} 2$ & $7,30 \mathrm{a} 1$ \\
H-32-3-15-20 & 13 & $3,97 \mathrm{a} 1$ & $8,87 \mathrm{a} 1$ & $49,38 \mathrm{a} 1$ & $20,74 \mathrm{a} 2$ & $7,00 \mathrm{a} 1$ \\
H-136-1-14-10 & 23 & $3,35 \mathrm{a} 1$ & $13,06 \mathrm{a} 1$ & $44,80 \mathrm{a} 1$ & $20,40 \mathrm{a} 2$ & $6,70 \mathrm{a} 1$ \\
H-29-1-9-8 & 07 & $6,36 \mathrm{a} 1$ & $16,77 \mathrm{a} 1$ & $37,64 \mathrm{a} 1$ & $20,26 \mathrm{a} 2$ & $7,30 \mathrm{a} 1$ \\
H-136-1-14-14 & 24 & $5,25 \mathrm{a} 1$ & $12,23 \mathrm{a} 1$ & $41,90 \mathrm{a} 1$ & $19,80 \mathrm{a} 2$ & $6,30 \mathrm{a} 1$ \\
H-136-1-13-15 & 21 & $3,70 \mathrm{a} 1$ & $10,21 \mathrm{a} 1$ & $44,80 \mathrm{a} 1$ & $19,56 \mathrm{a} 2$ & $6,70 \mathrm{a} 1$ \\
RUBI 1192 & 30 & $4,81 \mathrm{a} 1$ & $11,41 \mathrm{a} 1$ & $39,33 \mathrm{a} 1$ & $18,52 \mathrm{a} 1$ & $7,30 \mathrm{a} 1$ \\
H-39-1-11-12 & 16 & $2,40 \mathrm{a} 1$ & $10,18 \mathrm{a} 1$ & $29,87 \mathrm{a} 1$ & $14,16 \mathrm{a} 1$ & $7,30 \mathrm{a} 1$ \\
H-30-2-6-16 & 10 & $5,82 \mathrm{a} 1$ & $14,92 \mathrm{a} 1$ & $20,02 \mathrm{a} 1$ & $13,60 \mathrm{a} 1$ & $6,00 \mathrm{a} 1$ \\
H-84-3-7-20 & 17 & $3,02 \mathrm{a} 1$ & $12,18 \mathrm{a} 1$ & $25,21 \mathrm{a} 1$ & $13,47 \mathrm{a} 1$ & $6,00 \mathrm{a} 1$ \\
Média & & $5,03 \mathrm{~A} 1$ & $11,78 \mathrm{~A} 2$ & $41,43 \mathrm{~A} 3$ & &
\end{tabular}

Médias seguidas da mesmas letras minúsculas na coluna e maiúsculas nas linhas não diferem pelo teste de agrupamento de médias Scott-knott $(\mathrm{P}<0,05)$.

Tabela 3. Incidência (Inc) e severidade (Sev) da ferrugem (médias sem transformação) por época de avaliação de 30 genótipos de $C$. arabica avaliados em Machado

\begin{tabular}{|c|c|c|c|c|c|c|c|c|c|}
\hline \multirow{3}{*}{ Progênie } & \multirow{3}{*}{$\mathbf{N}^{0}$} & \multicolumn{6}{|c|}{ Épocas } & \multirow{2}{*}{\multicolumn{2}{|c|}{ Média }} \\
\hline & & \multicolumn{2}{|c|}{$1(31 / 03)$} & \multicolumn{2}{|c|}{$2(15 / 05)$} & \multicolumn{2}{|c|}{$3(07 / 06)$} & & \\
\hline & & Inc & Sev & Inc & Sev & Inc & Sev & Inc & Sev \\
\hline H-29-1-3-12 & 03 & $7,3 \mathrm{~b}$ & $0,9 \mathrm{~b}$ & $8,8 \mathrm{c}$ & $1,3 \mathrm{~b}$ & $14,7 \mathrm{c}$ & $6,02 \mathrm{~b}$ & $10,3 \mathrm{c}$ & $2,8 \mathrm{a}$ \\
\hline H-29-1-3-19 & 04 & $4,0 \mathrm{~b}$ & $1,9 \mathrm{~b}$ & $9,9 \mathrm{c}$ & $1,1 \mathrm{~b}$ & $16,7 \mathrm{c}$ & $3,43 \mathrm{~b}$ & $8,9 \mathrm{c}$ & $2,1 \mathrm{a}$ \\
\hline H-29-1-8-5 & 05 & $0,7 \mathrm{~b}$ & $0,3 \mathrm{~b}$ & $2,0 \mathrm{c}$ & $0,7 \mathrm{~b}$ & 6,7 c & $1,33 \mathrm{~b}$ & $3,1 \mathrm{c}$ & $0,7 \mathrm{~b}$ \\
\hline H-29-1-8-16 & 06 & $4,0 \mathrm{~b}$ & $1,0 \mathrm{~b}$ & $4,0 \mathrm{c}$ & $1,0 \mathrm{~b}$ & $31,3 \mathrm{~b}$ & $2,60 \mathrm{~b}$ & $13,1 \mathrm{c}$ & $1,5 b$ \\
\hline H-29-1-9-8 & 07 & $12,7 \mathrm{~b}$ & $1,1 \mathrm{~b}$ & $5,3 c$ & $0,7 \mathrm{~b}$ & $12,7 \mathrm{c}$ & $1,90 \mathrm{~b}$ & 10,2 c & $1,2 \mathrm{~b}$ \\
\hline H-29-1-14-5 & 08 & $11,3 \mathrm{~b}$ & $1,6 \mathrm{~b}$ & $7,1 \mathrm{c}$ & $0,7 \mathrm{~b}$ & $20,1 \mathrm{c}$ & $2,46 \mathrm{~b}$ & $12,9 \mathrm{c}$ & $1,6 \mathrm{~b}$ \\
\hline H-30-2-6-11 & 09 & $19,3 \mathrm{~b}$ & $1,6 \mathrm{~b}$ & $49,1 \mathrm{a}$ & $2,4 \mathrm{~b}$ & 69,6 a & $7,76 \mathrm{~b}$ & $46,0 \mathrm{a}$ & $3,9 a$ \\
\hline H-30-2-6-16 & 10 & $24,0 \mathrm{~b}$ & $1,1 \mathrm{~b}$ & $21,2 \mathrm{~b}$ & $2,1 \mathrm{~b}$ & $54,8 \mathrm{a}$ & $3,17 \mathrm{~b}$ & 33,3 a & $2,1 \mathrm{a}$ \\
\hline H-32-3-15-20 & 13 & $5,3 \mathrm{~b}$ & $07 \mathrm{~b}$ & $0,0 \mathrm{c}$ & $0,0 \mathrm{~b}$ & $1,3 \mathrm{c}$ & $0,66 \mathrm{~b}$ & $2,2 \mathrm{c}$ & $0,4 \mathrm{~b}$ \\
\hline H-32-11-17-4 & 15 & $12,0 \mathrm{~b}$ & $1,3 \mathrm{~b}$ & $0,0 \mathrm{c}$ & $0,0 \mathrm{~b}$ & $1,3 \mathrm{c}$ & $0,83 \mathrm{~b}$ & $4,4 \mathrm{c}$ & $0,7 \mathrm{~b}$ \\
\hline H-86-1-7-11 & 19 & $8,0 \mathrm{~b}$ & $0,4 \mathrm{~b}$ & $10,0 \mathrm{c}$ & $1,6 \mathrm{~b}$ & $10,1 \mathrm{c}$ & $1,3 \mathrm{~b}$ & $9,4 \mathrm{c}$ & $1,1 \mathrm{~b}$ \\
\hline H-136-1-9-10 & 20 & $26,0 \mathrm{~b}$ & $2,4 \mathrm{~b}$ & $55,7 \mathrm{a}$ & $3,2 \mathrm{~b}$ & $68,0 \mathrm{a}$ & $6,9 \mathrm{~b}$ & 49,9 a & $4,2 \mathrm{a}$ \\
\hline H-136-1-13-15 & 21 & $11,3 \mathrm{~b}$ & $1,1 \mathrm{~b}$ & $29,6 \mathrm{~b}$ & $2,6 \mathrm{~b}$ & $47,0 \mathrm{a}$ & $4,7 \mathrm{~b}$ & $29,3 \mathrm{~b}$ & $2,8 \mathrm{a}$ \\
\hline H-136-1-19-4 & 27 & $15,3 \mathrm{~b}$ & $1,2 \mathrm{~b}$ & $14,4 \mathrm{~b}$ & $2,1 \mathrm{~b}$ & $26,7 \mathrm{~b}$ & $4,9 \mathrm{~b}$ & $18,8 \mathrm{~b}$ & $2,7 \mathrm{a}$ \\
\hline H-136-1-19-7 & 28 & $8,0 \mathrm{~b}$ & $1,1 \mathrm{~b}$ & $13,2 \mathrm{c}$ & $1,5 \mathrm{~b}$ & $33,3 \mathrm{~b}$ & $2,6 \mathrm{~b}$ & $18,2 \mathrm{c}$ & $1,7 \mathrm{~b}$ \\
\hline H-138-1-4-3 & 29 & $3,3 \mathrm{~b}$ & $1,4 \mathrm{~b}$ & 5,3 c & $3,4 \mathrm{~b}$ & $22,4 \mathrm{~b}$ & $1,9 \mathrm{~b}$ & 10,3 c & $2,3 \mathrm{a}$ \\
\hline RUBI 1192 & 30 & $9,3 \mathrm{~b}$ & $1,4 \mathrm{~b}$ & 51,9 a & $2,8 \mathrm{~b}$ & 64,5 a & $3,5 \mathrm{~b}$ & 41,9 a & $2,6 \mathrm{a}$ \\
\hline Média & & $12,7 \mathrm{~B}$ & $1,5 \mathrm{~B}$ & $21,2 \mathrm{~A}$ & $2,0 \mathrm{~B}$ & 37,1 A3 & $4,5 \mathrm{~A}$ & & \\
\hline
\end{tabular}

Médias seguidas das mesmas letras minúsculas na coluna e maiúsculas nas linhas não diferem entre si pelo teste Scott-knott (P < 0,05). 
Quando se considera a média das três avaliações, podese observar que houve, a formação de três grupos de progênies para as duas características avaliadas. Para a característica incidência da ferrugem, destacaram-se 11 progênies com menor incidência, com valores variando de 2,2 a $18,2 \%$. Para a severidade da ferrugem, destacaram-se oito progênies com menor severidade e valores entre 0,4 e 1,1. O cultivar Rubi MG 1192 ficou entre os que mais apresentaram incidência da doença (41,9\%) e no grupo intermediário para severidade $(2,6)$, mostrando que as progênies apresentam variabilidade para resistência à ferrugem. As progênies de número 13, 15 e 19 mostraram-se promissoras para seleção em relação à resistência, por apresentar baixa incidência e severidade da ferrugem. Além disso, outro fato importante para seleção dessas progênies é que, à exceção da progênie 19, todas ficaram no grupo das mais produtivas na média das seis colheitas avaliadas.

Quanto à seleção de progênies com possibilidade de apresentar resistência do tipo não específica, destacaram-se as de número 19 e 28, que, embora tenham manifestado sintoma da doença, ocorreu com baixa incidência e, principalmente, baixa severidade, sendo a última característica indicativa de resistência horizontal, conforme proposto por Ribeiro et al. (1981). A incidência intermediária é importante, considerando-se que não é possível selecionar progênies com resistência horizontal naquelas que não apresentaram sintomas da doença, pois elas, provavelmente, têm resistência do tipo vertical ou específica, que encobre a resistência não-especifica. Uma explicação sugerida para o material estudado apresentar, além da resistência específica, a expressão da resistência não-específica é, presumivelmente, o cultivar Icatu ser um dos parentais e ter os dois tipos de resistência, como informam Alvarenga et al. (1998); Costa \& Ribeiro (1975) e Eskes \& Costa (1983). Os últimos autores encontraram progênies moderadamente resistentes, o que indica, possivelmente, resistência do tipo horizontal ou não específica. O germoplasma de Catimor, o outro parental utilizado na obtenção das progênies em estudo, provavelmente também apresenta resistência horizontal, como comprovado por Almeida (1980) e Zambolim et al. (2000) ao observarem menor severidade e período de incubação em descendentes de Catimor, comparados ao Catuaí Vermelho IAC 15’ sabidamente suscetível.

\section{CONCLUSÕES}

Pelos resultados obtidos pode-se concluir que entre as progênies avaliadas há a presença de variabilidade para produção e resistência à ferrugem, fato confirmado pelas estimativas da herdabilidade, que foram de boa magnitude. Esses resultados, juntamente com altas médias de produtividade, bom vigor vegetativo e comprovada resistência à ferrugem, permitem a seleção de progênies promissoras.

\section{REFERÊNCIAS}

Allard RW (1971) Princípios do melhoramento genético de plantas. São Paulo, Edgard Blücher, 381p.

Almeida LC de (1980) Resistência vertical e horizontal à Hemileia vastatrix Berk et $\mathrm{Br}$. e gerações $\mathrm{F}_{4}$ e $\mathrm{F}_{5}$ de progênies de cafeeiros Catimor. Dissertação de Mestrado. Universidade Federal de Viçosa, Viçosa. 40p

Alvarenga AP de, Ribeiro do Vale FX, Martinez HEP \& Pereira AA (1998) Produtividade e resistência a ferrugem em progênies de cafeeiro Icatu. Ciência e Agrotecnologia, 22:182-187.

Barbosa JC, Caixeta ET, Zambolim EM, Capucho AS, Rufino RN, Alvarenga SM, Zambolim L \& Sakiyama NS (2005) Caracterização da resistência vertical e horizontal do cafeeiro a ferrugem (Hemileia vastatrix Berk. \& Br) em acesso de Híbrido de Timor In: 4 Simpósio de Pesquisa Cafés do Brasil, Londrina. Resumos expandidos, Brasília-EMBRAPA. CDROM.

Bonomo P, Cruz CD, Viana JMS, Pereira AA \& Oliveira VR de \& Carneiro PCS (2004) Avaliação de progênies obtidas de cruzamentos de descendentes do Híbrido de Timor com as cultivares Catuaí Vermelho e Catuaí amarelo. Bragantia, 63:207-219.

Carvalho A, Medina Filho H P, Fazuoli L C, Guerreiro Filho O \& Lima MMA (1991) Aspectos genéticos do cafeeiro. Revista Brasileira de Genética, 14:135-183.

Carvalho A, Mônaco L C \& Fazuoli LC, (1979) Melhoramento do café XL - Estudos de progênies e híbridos de café Catuaí. Bragantia, 38:202-216.

Carvalho VL de \& Chalfoun SM (1998) Manejo integrado das principais doenças do cafeeiro. Informe agropecuário, 19:2735.

Carvalho A, Fazuoli LC \& Costa WM (1989) Produtividade do Híbrido Timor, de seus derivados e outras fontes de resistência a Hemileia vastatrix. Bragantia, 48:73-86.

Castilho-Zapata J \&, Moreno-Ruiz G (1981) Seleccion de cruzamientos derivados del Híbrido de Timor em la obtencion de variedades meloradas de café para Colômbia. Cenicafé, 32:3753.

Chalfoun SM \& Zambolim L (1985) Ferrugem do cafeeiro. Informe agropecuário, 11:42-46.

Chaves G M (1976) Melhoramento do cafeeiro visando a obtenção de cultivares resistentes a Hemileia vastatrix Berk et $\mathrm{Br}$. Revista Ceres, 23:321-332.

Correa LVT (2004) Adaptabilidade e estabilidade de progênies de cafeeiro Icatu. Dissertação de Mestrado. Universidade Federal de Lavras, Lavras. 55p.

Costa WM (1978) Relação entre o grau de resistência a Hemileia vastatrix e produtividade no café Icatu. Bragantia, 37:1-9.

Costa WM \& Ribeiro IJA (1975) Resistência a $H$. vastatrix observada no café Icatu. In: $3^{\circ}$ Congresso Brasileiro de Pesquisas Cafeeiras, Curitiba. Resumos, IBC-GERCA. p.113.

Cruz CD \& Carneiro PCS (2003) Modelos biométricos aplicados ao melhoramento genético. $2^{\mathrm{a}}$ ed. Viçosa, UFV. 585p.

Eskes A \& Costa WMda (1983) Characterization of incomplete resistance to Hamileia vastatrix in Icatu coffee population. Euphytica, 32:649-655.

Eskes A B (1980) Bases genéticas da resistência horizontal a patógenos em plantas. Ciência e Cultura, 32:1464-1472.

Fazuoli LC, Carvalho A, Costa WM da, Nery C, Laun CRP \& Santiago M (1983) Avaliação de progênies e seleção no cafeeiro Icatu. Bragantia, 42:179-189. 
Fazuoli LC, Guerreiro Filho, Medina Filho HP \& Silvarola MB (2000) Estimação de parâmetos genéticos e fenotípicos em progenies do café Icatu. In: $1^{\circ}$ Simpósio de Pesquisas dos Cafés de Brasil, Poços de Caldas. Resumos expandidos, Minasplan. p.494-499.

Ferreira D F (2000) Análises estatísticas por meio do Sisvar para Windows versão 4.0. In: 45 ${ }^{\mathrm{a}}$ Reunião da Região Brasileira da Sociedade Internacional de Biometria, São Carlos. Anais, UFSCar. p.255-258.

Matiello JB (1991) O café: do cultivo ao consumo. São Paulo, Editora Globo. 357p

Mendes, ANG (1994) Avaliação de metodologias empregadas na seleção de progênies do cafeeiro (Coffea arabica L.). Tese de doutorado. Universidade Federal de Lavras, Lavras. 167p.

Miranda JM (2003) Avaliação de progênies de cafeeiro quanto a herdabilidade, correlações fenotípicas, produtividade e resistência a ferrugem. Tese de Doutorado. Universidade Estadual PaulistaFaculdade de Ciências Agrárias e Veterinárias, Jaboticabal. 101p.

Moura WM, Pereira AA, Bartholo GF, Kochem MG \& Reis LM (2001) Avaliação de progênies $F_{3}$ resultantes de cruzamentos de Catuaí e Mundo novo com Híbrido de Timor e Catimor na região de Patrocínio, Alto Paranaíba, Minas Gerais. In: $2^{\circ}$ Simpósio de Pesquisa Cafes do Brasil, Vitória. Resumos expandidos, Embrapa/MINASPLAN. p.1279-1284.

Pereira AA (1995) Herança da resistência a Hemileia vastatrix Berk. Et Br. Em cafeeiros derivados de Híbrido de Timor. Tese de Doutorado. Universidade Federal de Viçosa, Viçosa. 96p.

Pereira AA, Moura WM, Bartholo GF, Sakiyama NS, Zambolim L, Kochem MG \& Amaral MA (2001) Comportamento de progênies resultantes de cruzamentos de catuaí Amarelo com Híbrido de Tímor, na Região de São Sebastião do Paraíso, Sul de Minas Gerais. In: $2^{\circ}$ Simpósio de Pesquisa Cafes do Brasil, Vitória. Resumos expandidos, Embrapa/MINASPLAN. p.1312-1318.

Ramalho MAP, Ferreira DF \& Oliveira AC de (2000) Experimentação em genética e melhoramento de plantas. Lavras, UFLA. 326p.
Ribeiro IJA, Bergamim Filho A \& Carvalho PCT (1981) Avaliação da resistência horizontal a Hemileia vastatrix Berk et Br. em cultivares de Coffea arabica L. em condições naturais de epidemia. Summa Phytopathologicacaba, 7:80-95.

Severino L S, Sakiyama NS, Pereira AA, Miranda GV \& Zambolim L (2000) Seleção de progênies de Catimor (Coffea arabica L.) em Martins Soares In: $1^{\circ}$ Simpósio de Pesquisa Cafes do Brasil, Poços de Caldas. Resumos expandidos, Embrapa/MINASPLAN. p.522-526.

Srinivasan CS, Vishershwra S \& Susvamanya H (1979) Genotypeenviromental interaction and hertability yeld in Coffea arabica L. Journal of Coffe Research, 9:69-73.

Steel RG \& Torrie JK (1980) Principles and procedures of statistics: a biometrical approach. $2^{a}$ ed. Tokyo, McGraw-Hill. 633p.

Van Der Plank JE (1968) Disease resistance in plants. New York, Academic Press. 206 p.

Van Der Plank JE (1963) Plants disease: epidemics and control. New York, Academic Press. 349p.

Várzea VMP, Rodrigues Jr CJ, Silva M do CM L, Gouveia M, Marques DV, Guimarães LG \& Ribeiro A (2002) Resistência do cafeeiro a Hemileia vastatrix. In: Zambolim L (Ed.) O Estado da arte de tecnologias na produção de café. Viçosa, UFV. p.297320 .

Zadoks JC (1972) Reflecions on disease resistance in annual crops. In: Bingham R T, Hoff RJ \& Mc Donald GI. (Eds) Biology of rust resistance in foresst trees: proceedings of a Nato-Iufro advacend study Institute. U.S. Department of Forest Service, Miscelaneous Publishing. p.43-63.

Zambolim L, Pereira AA, Sakiyama NS \& Barros UV (2000) Resistência genética e componentes de resistência de linhagens de Catimor em gerações $\mathrm{F}_{6}$ e $\mathrm{F}_{7}$ à raças de Hemileia vastatrix-BERK. et Br. In: $1^{\circ}$ Simpósio de Pesquisa Cafes do Brasil, Poços de Caldas. Resumos expandidos, Embrapa/MINASPLAN. p.507514. 